Miriam Becker, Ph.D. em zoologia (Imperial

College of Science \& Technology, University of

London). Professora adjunto do Departamento

de Zoologia (UFRGS), professora de ecologia

de populações (UFRGS), pesquisadora do

Centro de Ecologia do Instituto de Biociências da UFRGS, pesquisadora em biologia e ecologia de insetos.

\title{
O homem frente às pragas
}

Hoje, a principal preocupação do homem em relação aos insetos se concentra nos danos que algumas das espécies causam. Estima-se que estes danos atinjam, a cada ano, de 10 a $15 \%$ da produção agrícola mundial. Qual seria, então o procedimento a ser adotado em relação a estes poderosos e minúsculos seres que se apropriam de tal porção do alimento produzido pelo homem? Dentro de um ponto de vista imediatista, a erradicação, ao menos local, das espécies que nos são nocivas pareceria o mais desejável, entretanto o custo seria demasiado alto.

Já são bem conhecidas as conseqüências desastrosas sobre o meio ambiente causadas por medidas drásticas que buscam erradicar os insetos. Manutenção do equilíbrio ambiente e desenvolvimento econômico parecem, às vezes, serem objetivos conflitantes e, no entanto, devem, como meta, ser dirigidos a um fim comum - melhor vida para o homem. Na prática, em geral, os técnicos do desenvolvimento econômico seguem tendências que buscam principalmente o aumento quantitativo da produção, e aqueles que se ocupam .com a ciência da conservação da natureza também buscam o crescimento quantitativo da produção. Estes, no entanto, preocupam-se em igual medida com o manejo de aspectos qualitativos do ambiente que não podem ser medidos de imediato, e com igual facilidade, por padrões monetários precisos. Em ambos os casos, as regras físicas e biológicas que determinam a vida na terra não podem ser esquecidas. O conhecimento adequado das relações dos seres vivos com seu ambiente propicia melhores metas de desenvolvimen-
Miriam Becker 
mento na abundância da praga; e mantê-la em baixos níveis de densidade. O inseto-praga é, em essência, uma entidade biológica e o seu manejo, até um nível tolerável, é um problema de ecologia aplicada. Os ambientes criados pelo homem com a agricultura (agroecossistemas), onde a ocorrência de pragas é um fato comum, diferem dos ambientes naturais (ecossistemas naturais) em muitos aspectos. Nestes, há ocorrência só ocasional em ecossistemas pouco complexos e não há registros de ocorrências em florestas tropicais úmidas. Isto, naturalmente, é de grande relevância para o conceito de "manejo de pragas".

\section{Diversidade $x$ simplicidade}

Há bastante tempo se reconhece que são relativamente simples as comunidades bióticas dos ambientes onde predominam condições climáticas adversas e que apresentam baixa densidade, isto é, suportam relativamente poucas espécies de animais e vegetais. No outro extremo, onde é observada a maior diversidade de formas animais e vegetais, encontram-se as regiões tropicais úmidas, onde o clima é relativamente estável e favorável à vida. Nas florestas tropicais pluviais, por exemplo, estima-se em vários milhares o número de espécies de vegetais e de animais que ali vivem. Em contraste, comunidades simples, tais como a tundra ártica, suportam um número consideravelmente menor de espécies, talvez em torno de algumas centenas.

Nestes tipos de comunidades simples, com pouca "riqueza" de espécies, é freqüente a ocorrência de desproporções no número de indivíduos por espécie, o que não acontece em comunidades naturais altamente complexas, onde existem números relativamente altos de indivíduos de uma única espécie. Nas primeiras, ainda, podem ocorrer, também, grandes flutuações nos números de indivíduos de algumas das espécies de ano a ano, não ocorrendo, porém, no segundo caso, devido à ocorrência de um maior número de interações entre as espécies ali existentes, trazendo, como conseqüência, uma maior estabilidade ao sistema.

Entre os dois extremos aqui mencionados, encontra-se uma ampla gama de variações de complexidade nas comunidades naturais.

\section{A simplificação introduzida pelo homem}

Os agroecossistemas - ambiente simplificado, criado pelo homem - diferem entre si dentro de um espectro muito mais estreito; variam em função do tempo de permanência, do isolamento e da diversidade das espécies. Em conseqüência, a potencialidade para o maneio das pragas varia de acordo com as diferentes características que os diferentes agroecossistemas apresentam.

Os agroecossistemas não se autoperpetuam: são sempre de duração limitada, que pode ser maior, em certos tipos de pomares ou florestas cultivadas, ou ser extremamente breve, como em algumas culturas onde a colhieita se dá poucos meses após o plantio. Eles se iniciam de forma abrupta, geralmente após a eliminação da vegetação ali preexistente. Ao contrário dos agroecossistemas, os ecossistemas naturais se autoperpetuam; alguns são praticamente permanentes e outros, como a vegetação efêmera dos desertos ou a vegetação arbustiva que se estabelece em áreas perturbadas, são mais temporários, mas, geralmente, apresentam uma continuidade no espaço.

O homem costuma plantar a espécie vegetal que mais the interessa e por isso os agroecossistemas em geral apresentam uniformidade, onde a ausência de diversidade vegetal se acentua pelo uso de herbicidas, enquanto que nos ecossistemas naturais a vegetação é o produto da seleção natural. No ambiente simplificado criado pelo homem, a homogeneidade também diz respeito à idade das plantas e às cultivares selecionadas. Isto traz como conseqüência uma sincronização nos processos de crescimento, florescimento, frutificação, etc. de forma muito mais marcada do que em ecossistemas naturais.

\section{Diversidade e estabilidade}

Muitas das espécies de insetos que atingem altas densidades em agroecossistemas e, porque causam prejuízos econômicos ao homem, são classificadas como "pragas", com freqüência não são abundantes em seus ambientes naturais, fenômeno que pode ser atribuído às complexas interações existentes nas comunidades naturais. Nestes ambientes, as tendências para um aumento nos números parecem estar contrabalanceadas por uma série de pressões opostas a este mesmo crescimento. Esta complexidade encontrada nas condições naturais é estabilizadora, e contrasta com o conjunto simplificado de condições apresentadas pelo agroecossiste$\mathrm{ma}$, onde ocorrem poucos dos mecanismos controladores que se desenvolvem e operam nos ambientes naturais.

\section{O surgimento das pragas}

Os níveis de abundância dos insetos são determinados pelas características da biologia e ecologia da espécie e do ambiente onde vivem, tais como, exigências em termos de alimento e de condições físicas (temperatura, umidade relativa, etc.) e 
a extensão com que o ambiente preenche estas necessidades; capacidade de reprodução sob condições ambientais favoráveis; presença e abundância de inimigos naturais (parasitas, predadores e patógenos) e de competidores.

Com freqüência, as pragas são criadas pelo homem; espécies que ocorrem em baixos números em seus ambientes naturais podem atingir enormes densidades nas condições criadas pelo homem, que podem propiciar um melhor suprimento de algum fator até então limitante ao aumento dos números, tal como o alimento, praticamente ilimitado numa extensa cultura homogênea. A extrema simplificação do sistema torna-o inadequado aos inimigos naturais da praga que, em condições naturais, poderiam vir a ser um importante fator para controlar o crescimento do número de indivíduos. $\mathrm{O}$ uso de inseticidas, que objetiva combater a praga, em geral mata, também, a maior parte de seus inimigos naturais. Acidentalmente, por meio de plantas introduzidas, o homem pode acabar por introduzir, também, insetos para as novas regiões que, na ausência dos mecanismos de controle natural existentes na sua região de origem (parasitas, predadores, patógenos, competidores, etc.), podem atingir proporções de praga.

\section{As estratégias dos insetos}

Assim como a morfologia dos seres vivos é a conseqüência da seleção natural, também os padrões da biologia são moldados pela seleção natural, que tem por objetivo, naturalmente, o aumento dos números de indivíduos quando as condições são favoráveis e a sobrevivência do mínimo necessário quando as condições são desfavoráveis. A seleção natural, portanto, otimiza a sobrevivência e o crescimento populacional nas condições ambientais que a espécie encontra nos lugares que tipicamente ocupa, observando-se que estes padrões têm uma estreita relação com o habitat. As espécies associadas a habitats instáveis são, dentro desta perspectiva, denominadas espécies "oportunistas" ou "colonizadoras". Nestas, em geral, os indivívuos têm as seguintes características: pequeno porte; alta mobilidade e tendência à migração; amadurecimento sexual rápido e início precoce da reprodução; produção de uma grande prole por indivíduos; gerações curtas. Em contraste, as espécies associadas a habitats estáveis apresentam como características: maior porte; baixa tendência à migração; amadurecimento sexual mais lento e início mais tardio da reprodução; produção de uma pequena prole por indivíduo, porém, mais apto à competição; gerações longas. No primeiro caso, onde as condições favoráveis à sobrevivência e à reprodução são de curta duração em relação ao ciclo de vida dos organismos, a melhor es- tratégia consiste em tirar o máximo proveito desta situação enquanto ela persistir. A estratégia reprodutiva se concentra em alocar o máximo matéria e energia na reprodução, produzindo o maior número de filhos o mais cedo possível e, no segundo caso, onde são persistentes as condições favoráveis, esta estratégia só levaria a uma exacerbada competição entre os indivíduos e a uma superexploração dos recursos disponíveis. Nestes ambientes saturados, a melhor estratégia consiste em produzir um pequeno número de filhos, porém mais aptos à competição e, portanto, com maiores probabilidades de sobrevivência por indivíduo. Em ecologia, as primeiras são denominadas espécies tipo " $r$ " (maximizam produtividade) e as segundas, espécies tipo "K" (maximizam eficiência).

\section{Novas perspectivas}

Os efeitos secundários indesejáveis dos inseticidas podem ser considerados uma das principais razões para os esforços empreendidos pelos entomólogos nos últimos anos na busca de uma satisfatória estratégia de controle de pragas. Estes esforços se dirigiram tanto para a pesquisa de campo e de laboratório quanto para o estabelecimento das necessárias bases teóricas e leis genéricas.

As abordagens são diversas, entre as quais se postula o uso do controle biológico clássico, que consiste na descoberta, importação, introdução e estabelecimento de novos inimigos naturais da praga (parasitas, predadores e patógenos) originários de outras regiões. Nos últimos anos, outras formas de controle biológico vem sendo tentadas, tais como as técnicas de "macho estéril", que consiste na liberação de um grande número de adultos da praga, esterilizados por meios químicos ou por radioatividade - se uma proporção alta das fêmeas copular com indivíduos estéreis, a taxa de reprodução baixará e os números da população, em decorrência, declinarão - ; e as técnicas de "controle bioquímico" que lança mão de compostos orgânicos ocorridos na natureza e que são capazes de influenciar o comportamento dos insetos, atraindo-os, repelindo-os, etc.

Uma outra abordagem é aquela em que se utiliza inseticidas conjugados ao controle biológico, especialmente com parasitas e predadores, devendo, nestes casos, o inseticida ser o mais seletivo possível, isto é, ser tóxico para o menor número de espécies afora o seu alvo - a praga. Os inimigos naturais como fonte de mortalidade da praga podem ser introduzidos de forma planejada no agroecossistema; porém, também, ser simplesmente protegidos, evitando-se danos aos que ali já ocorrem naturalmente.

Uma abordagem mais abrangente de contro- 
le é aquela denominada manejo integrado de pragas, onde busca-se adicionar ao uso dos inseticidas seletivos e ao uso dos inimigos naturais eficientes todos aqueles elementos que possam ser relevantes ao controle dos números da praga. Este é o mais recente capítulo da história do homem na busca de uma solução para o problema, onde este lança mão de técnicas desenvolvidas isoladamente em várias áreas e as integra num contexto mais amplo, sendo necessário, para seu sucesso, ter-se um amplo conhecimento da biologia e da ecologia do insetopraga. Para cada caso em particular são necessárias pesquisas muitas vezes caras e demoradas que nortearão os procedimentos a serem adotados. Os programas devem ser dinâmicos, envolvendo levantamento contínuo de informações e avaliação dos resultados, não devendo existir nenhuma rigidez préprogramada; as ações de controle evoluem na medida das necessidades, isto é, em função do desenvolvimento da praga.

As pesquisas nos campos da teoria e da prática nestes últimos anos permitiram uma melhor compreensão da dinâmica das populações de insetos, necessária às diretrizes apropriadas para os métodos de controle para diferentes pragas. Diferentes estratégias de controle terão desigual eficiência em função dos padrões da biologia e da ecologia da praga, e das características do habitat (agroecossistema). Em relação ao habitat, importa fundamentalmente o espaço de tempo em que ele se encontra em condições adequadas à reprodução da população da praga considerada e em relação à própria praga interessa a velocidade com que os indivíduos atingem a maturação sexual e começam a se reproduzir. As pragas tipo " $r$ " são características de agroecossistemas com curta vigência de condições adequadas; elas geralmente atingirão níveis que cheguem a causar danos consideráveis se um número suficiente de indivíduos invadir a cultura em tempo hábil. Os inimigos naturais - parasitas e predadores - serão de pouca significância nestes casos e as tentativas de controle biológico terão pouco sucesso. No seu manejo, as práticas agriculturais terão grande expressão, podendo reduzir as probabilidades de invasão e estabelecimento da praga na cultura, sendo, da mesma forma, importante selecionar variedades resistentes ao ataque. Para combater estes tipos de praga, caracterizadas pelo crescimento explosivo, os inseticidas ainda serão a maior arma e o seu uso racional deverá ser norteado por métodos que permitam acompanhar o desenvolvimento da praga na cultura.

As pragas do tipo " $k$ " são características dos agroecossistemas que apresentam longa vigência de condições adequadas, que podem ser controladas por uma ampla gama de métodos, desde alguma forma de alteração do habitat até técnicas que interfiram negativamente com a reprodução, tais como, o uso de machos estéreis e o controle bioquímico utilizando hormônios sexuais que impeçam a realização da cópula.

Entre estes dois extremos encontra-se todo um espectro de pragas intermediárias no contínuo " $r$ " - " $k$ ", assim como de habitats intermediários em termos de vigência de condições favoráveis. Para cada uma destas pragas, a estratégia adequada é aquela que faz uso de variedades resistentes, de alterações no ambiente que tornem o agroecossistema menos adequado à sobrevivência e à reprodução e, em especial, de inimigos naturais. O uso regular de inseticidas, nestes casos, trará maior prejuízo do que benefício, pois, causando a morte dos inimigos naturais romperá o desejado balanço, promovendo o reaparecimento da praga em maiores números.

Um verdadeiro programa de manejo pode ser seriamente limitado pela ausência das informações básicas essenciais. Neste contexto, o papel do entomólogo é cada vez mais amplo, na busca de meIhor vida para o homem através de uma coexistência tolerável com os insetos.

\section{Bibliografia}

1. GLASS, E. H. Intergrated pest management; rationale, potential, needs and implementation. Entomological Society of America Special Publication, 75-2. 1975. $141 \mathrm{p}$.

2. PIANKA, E.R. Evolutionary ecology. S.I., Harper \& Row, 1974. $356 \mathrm{p}$.

3. SOUTHWOOD, T.R.E. Habitat, the templet for ecological strategies? Journal Animal Ecology 46: 337-365, 1977.

4. \& WAY, M.J. Ecological background to pest management: In. RABB, R.T. \& GUTHRIE, F.E. ed Concepts pest management. Raleigh, N.C. State University, 1970. p. 6-28

5. WATT, K.E.F. Ecology and resource management. New York, McGraw Hill, 1968. 450 p. 